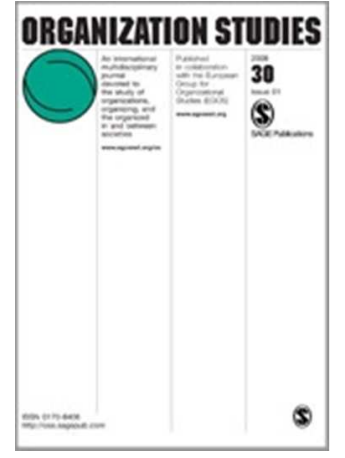

\title{
Resistance through Difference: The Co-Constitution of Dissent and Inclusion
}

\begin{tabular}{|c|c|}
\hline Journal: & Organization Studies \\
\hline Manuscript ID & OS-14-0834.R3 \\
\hline Manuscript Type: & $\begin{array}{l}\text { Special Issue: Resistance, resisting, and resisters in and around } \\
\text { organizations }\end{array}$ \\
\hline Keywords: & $\begin{array}{l}\text { Resistance, difference, normative control, discourse, inclusion, social } \\
\text { diversity, leadership development }\end{array}$ \\
\hline Abstract: & $\begin{array}{l}\text { This article argues that discursive constructions of difference can shape } \\
\text { practices of organizational resistance. Drawing on an inductive study of } \\
\text { international teams in a global leadership programme, the paper reveals } \\
\text { how difference is discursively produced and reproduced in team members' } \\
\text { talk. In conditions of normalizing control, the majority of teams engage in } \\
\text { individuating practices that reinforce internal differences, preclude group } \\
\text { cohesion and marginalize certain members. One team, however, explicitly } \\
\text { resists programme stipulations in ways that express members' } \\
\text { heterogeneity and simultaneously reinforce group solidarity. Referring to } \\
\text { these oppositional practices as 'resistance through difference', the article } \\
\text { describes how dissent challenges the hierarchies and disciplinary practices } \\
\text { embedded in the leadership programme, and theorizes the co-constitution } \\
\text { of inclusion and resistance. By examining the construction of difference not } \\
\text { as 'a problem', but as a productive resource, the paper also addresses the } \\
\text { generative outcomes of this managerial resistance. We argue that } \\
\text { 'resistance through difference' is an important form of dissent that could } \\
\text { well become more prevalent as globalized business processes expand. }\end{array}$ \\
\hline
\end{tabular}

\section{SCHOLARONE ${ }^{m}$ \\ Manuscripts}




\title{
Resistance through Difference: The Co-Constitution of Dissent and Inclusion
}

\begin{abstract}
:
This article argues that discursive constructions of difference can shape practices of organizational resistance. Drawing on an inductive study of international teams in a global leadership programme, the paper reveals how difference is discursively produced and reproduced in team members' talk. In conditions of normalizing control, the majority of teams engage in individuating practices that reinforce internal differences, preclude group cohesion and marginalize certain members. One team, however, explicitly resists programme stipulations in ways that express members' heterogeneity and simultaneously reinforce group solidarity. Referring to these oppositional practices as 'resistance through difference', the article describes how dissent challenges the hierarchies and disciplinary practices embedded in the leadership programme, and theorizes the co-constitution of inclusion and resistance. By examining the construction of difference not as 'a problem', but as a productive resource, the paper also addresses the generative outcomes of this managerial resistance. We argue that 'resistance through difference' is an important form of dissent that could well become more prevalent as globalized business processes expand.
\end{abstract}

Keywords: Resistance, difference, normative control, discourse, inclusion, social diversity, leadership development

\section{Introduction}

How do employees in international leadership development teams, some with considerable power and status as managers, respond to pressures to conform to culturally narrow ways of being? While relatively little research examines this question, such pressures are arguably increasingly common as international firms seek to manage and develop workforces drawn from different regions of the world. Exploring the ways in which members of international management teams negotiate difference, this article argues that their discursive constructions of difference can inform significant practices of workplace resistance. It therefore aims to contribute to the study of resistance by highlighting the importance of constructed difference within control/resistance processes and in particular how this can reflect and reinforce organizational dissent. 
Rather than treat control and resistance as separate binaries, scholars increasingly argue that this relationship is better viewed as inextricably inter-related, dialectical, and shaped by discourse (Mumby, 2005; Thomas \& Hardy, 2011). Inspired by the Foucauldian view that disciplinary practices invariably provoke opposition, this important focus on the 'control/resistance dialectic' points to the fluid, ambiguous and potentially contradictory character of the power relations through which resistance is typically enacted. It also suggests that asymmetrical power relations will not produce employee resistance in any simple, pre-defined or mechanical way. Control/ resistance dialectics are likely to bring a variety of dynamics and effects, many of which cannot be specified outside of particular local contexts (Collinson, 1994).

Although research on resistance continues to thrive, a key area that has received far less attention concerns the multiple ways in which employee difference(s) may inform control/ resistance dialectics in international work settings. Our conceptualization of difference(s) in organizations as mutable and multifaceted is informed by research that questions more static and sometimes essentialized notions of 'national culture' and cultural difference. Conventional approaches tend to discount power imbalances among identity groups and sidestep intersecting forms of subjectivity that are given particular meanings in specific contexts (Konrad, 2003). Conversely, with a few notable exceptions (from gender and post-colonial scholarship), research on organizational resistance has seldom considered constructions of difference relating to ethnicity, race or language, particularly in international contexts.

The focus in this article on resistance relating to international managerial teams reveals underexplored analytical links between contemporary forms of dissent, control, and difference. We present an inductive study drawing on the accounts of managers of sixteen nationalities in an employer-led international leadership programme. The paper focuses on the social construction of difference produced in situ and how this gives rise to forms of resistance to date unexamined in the literature. Specifically, we consider resistance dynamics found in project teams of international 
membership. While some teams construct difference in ways that reproduce programme-level normative controls and status hierarchies, the study uncovers oppositional practices that both draw upon and express team members' 'difference' from the culturally narrow norm manifest in the programme.

Drawing on these findings, we theorize the co-constitution of resistance and 'inclusion', the inclusion of difference, referred to here as 'resistance through difference', identifying a number of practices through which this co-constitution occurs. In addition to contributing to dialectical theories of resistance and control (see for example, Kondo, 1990; Collinson, 1994; Mumby, 2005), the findings have implications for emerging scholarship on inclusion, and for research on organizational teams and formalized learning programmes in international settings. The following sections consider literature on the control/resistance dialectic, first in relation to constructions of difference and then in relation to international team processes. This is followed by an explanation of the research site and the methods used in our fieldwork and analysis. Drawing on the accounts of team members and other key informants, the findings are structured around the discursive practices of the resistant team contrasted with one other, more typical, non-resisting team. We then discuss these findings and their implications, including directions for future research.

\section{Resistance in Contemporary Organizations}

Researchers of resistance have questioned traditional approaches that typically view dissent as 'dysfunctional', 'deviant', misguided and/or 'a barrier to change' (e.g. Coch \& French, 1948). Mainstream perspectives tend to treat oppositional practices either as of little consequence and therefore best tolerated or ignored, or as likely to incur significant cost and therefore best managed, minimized or eliminated (Kotter and Schlesinger, 1979). These accounts often dismiss dissent as the irrational behavior of 'troublemakers', and as an 'antisocial' expression of individual pathology (Giacalone \& Greenberg, 1997). By contrast, others show that there is much to learn from a deeper and more critical analysis of the conditions, processes, and consequences of 
organizational resistance (Courpasson \& Vallas, 2016; Thomas \& Hardy, 2011). They demonstrate how 'critical upward communication' (Tourish, 2013) can in turn produce crucial insights about the nature and underlying dynamics of organization. Contemporary debates emphasize the changing character of resistance in post-industrial organizations where management control is likely to be normative, ideological and focused on subjectivities in addition to its more material manifestations (Prasad \& Prasad, 2000; Thomas \& Davies, 2005a).

In relation to the conditions of resistance, scholars have problematized the managerial control strategies that characterize many organizations and that mainstream approaches typically take for granted (Edwards, 1979). They show how excessive, contradictory or inconsistent control practices can frequently act as a precursor for employee resistance (Burawoy, 1985). Writers have revealed important inter-relationships between resistance and the social organization of production, the asymmetrical nature of workplace power relations, and the material and symbolic insecurities that often characterize contemporary employment (Collinson, 2003; Giddens, 1979). Further, different forms of management control can (unintentionally) provide opportunities for different types of resistance (e.g. Hodson, 1995). These studies demonstrate that opposition does not operate in a vacuum, and, when studying resistance, we are also inevitably examining its important conditions of power and control.

Research on resistance also emphasizes the need to understand the varying processes through which dissent can be expressed. Studies demonstrate that, no matter how asymmetrical the power relations, employees find ways to resist (Jermier, Knights \& Nord, 1994). They can draw on a whole variety of technical knowledges, cultural resources and strategic agencies in mobilizing oppositional practices, which may be formal and/or informal, symbolic and/or material, collective and/or individual. Such practices enable employees to express discontent, exercise a degree of control over work processes and/or construct alternative, more positive identities to those prescribed by their organization (Prasad \& Prasad, 2000). Research demonstrates that employees 
are more likely to resist when they believe their interests have not been considered, when they perceive employers to be 'out of touch' and/or when they detect discrepancies between managers' policies and practices (Collinson, 2011). For many scholars, resistance practices are an important demonstration of employee agency, creativity and knowledgeability. Employees may also engage in disguised practices that embody elements of both dissent and consent through the management of impressions (Goffman, 1956). Under the gaze of authority and of organizational monitoring systems, individuals are increasingly aware of themselves as visible objects and, as a consequence, can become skilled choreographers of self and information. Emphasizing that resistance is not always planned or calculated, Prasad and Prasad (2000) uncover forms of dissent as 'strategies-inaction' that may be accidental or retrospectively constructed.

In addition to the conditions and processes of resistance, recent research examines its consequences (Mumby, 2005; Thomas \& Davies, 2005a, b). Some scholars argue that particular forms of resistance can have productive effects for the organization, in line with managers' interests (Courpasson, Dany \& Clegg, 2012). Others focus on the ways in which resistance can create greater autonomy, independence and dignity for resistors (Thomas \& Davies, 2005a, b), countering views that opposition is inevitably 'ironic', often serving the agenda of employers (Fleming \& Spicer, 2003). Rather, the effect of resistance can be to "stretch the iron cage", making the organization "a more habitable space for those for whom escape or exit is not a viable option" by continually redefining the boundaries of organizational control (Prasad \& Prasad, 2000: 402). This paper argues that the discursive construction of difference can be equally implicated in forms of resistance that redefine the boundaries of control.

\section{Control, Resistance and Difference}

Alongside studies of contemporary resistance are theorizations of organizational control as increasingly normative and disciplining of the self, relating to employees' 'insides' (Deetz, 1995), and functioning as "an attempt to elicit and direct the required efforts of members by controlling 
the underlying experience, thoughts and feelings that guide their actions" (Barley \& Kunda, 1992:11). Organizational research now recognizes the importance of such normative control and how it might discipline subjectivity and identity. However, as Mumby (2011) and Ashcraft (2011) point out, the ways in which control and resistance may invoke constructions of identity and of difference, particularly constructions associated with ethnicity, race or culture, have been seriously underexplored in this literature.

A small amount of empirical work looks directly at racialized minority employees' engagement with normative controls. Zanoni \& Janssens (2007) examine the ways in which minority workers in a Belgian setting uniquely experience both traditional and more implicit, normative control, but are also agents who actively comply with, accommodate and/or resist these pressures. Bell and Nkomo's (2001) studies of black female managers in the U.S. contribute similar findings. Hewlin (2003) theorizes 'facades of conformity' in which minority employees conform outwardly with dominant organizational values but privately resist assimilation. Focusing specifically on normalizing control, Ahonen, Tienari, Merilainen \& Pullen (2014) disclose the identity-'centering' effects of normalizing discourse, including in their case a discourse of workplace diversity itself that deems inalienably 'different' those outside the norm of traditional employees.

Mainstream research on social diversity specifically in international organizations has rarely taken up the question of how resistance may be intertwined with normalizing control. The bulk of this research considers difference from the perspective of more traditional cross-cultural management theory in which issues of power, control and opposition are rarely addressed (Brannen, 2009). 'Difference' tends to be viewed as immutable, and often benign with respect to power relations, rather than socially constructed and imbued with particular meanings in context. As argued by Ailon-Souday \& Kunda (2003: 1074), studies tend to "treat national identity as merely the passive embodiment of a predetermined cultural template" with the result that they fail 
to take into account the autonomy that members have in (re)defining the meaning(s) of national belonging in different contexts. Individuals' ability to resist impositions of culture or normative control is often not recognized. An important exception is Ailon-Souday \& Kunda's (2003, 2009) study of local Israeli opposition to a merger with a US company, bringing together themes of discursively constructed difference and dissent through a focus on the interplay between nationallevel identity and resistance, in this case to western globalization. We would add to their analysis the key additional importance of identities as sources of difference which may be racialized and gendered as well as national and cultural, and their potential interrelation with resistance (Alcoff, 2006).

More generally, research on control/resistance dynamics has seldom considered the importance of identities pertaining to nationality, race, culture and their intersections. There are a number of studies on control/resistance dialectics in relation to men and masculinity (e.g. Willis, 1977; Cockburn, 1983; Collinson, 1992) and women and femininity (e.g. Kondo, 1990; Pollert, 1981; Westwood, 1984). Yet, these studies tend to focus on shopfloor or manual work (Thomas \& Davies, 2005a \&b on resistance and gender in the public sector are important exceptions). There has been little research on how constructions of difference in international settings, especially involving senior managers, may shape resistance.

\section{Control, Resistance and Teamworking}

Seemingly ubiquitous in contemporary organizations, teamworking is often theorized to benefit productivity, innovation and engagement, through links to employee autonomy (e.g. Thompson, 2011). More critical scholars have also identified processes through which 'concertive' controls can curb team members' freedom and intensify managerial power (Ezzamel \& Willmott, 1998; Sewell 2001, 1998). Barker's (1993) seminal study demonstrated that teams may control the actions of members through progressively enforcing norms, producing a powerful control system. Sinclair (1992) argues that the positive rhetoric around organizational teams can itself constitute a 
form of control creating the "tyranny of a team ideology". Here, rhetoric paints the notion of the team as an attractive solution to a range of organizational problems, but in practice "camouflage(s) coercion and conflict with the appearance of consultation and cohesion" (Sinclair, 1992: 611).

Other studies demonstrate how conflict and power imbalances can be related directly to the presence of team members constructed as 'minorities' and thus of lower status (Foldy, Rivard \& Buckley, 2009; Konrad, 2003). The experience of such status in teams often provides grounds for exclusion and division (Reynolds \& Trehan, 2003). Literature discussing international teams specifically focuses both on opportunities and on areas of potential conflict in such teams. In this case, employee difference is often theorized in relation to macro-cultural differences (national differences) and issues arising there-from such as conflicting communication styles (Chevrier, 2003; Matveev \& Nelson, 2004). Here again, difference tends to be studied as a priori and static. While useful for raising awareness of differences, such reification tends to treat members of national cultures as directly 'representative' of a specific culture. This not only neglects the constructed character of both culture and difference, but also means that organizational and employment contexts remain secondary in the analysis.

The few available studies of resistance in teamworking tend to support arguments highlighting the importance of subtle and sometimes masked forms of dissent. In so doing, they also illustrate the importance of team resistance often expressed though humour, irony and satire. For example, employees in a US Subaru Isuzu plant detected inconsistencies between the company's teamworking ideal and work intensification (Graham, 1995). Consequently, they refused to participate in corporate rituals, sent highly critical anonymous letters to the company and used humour to make light of teamwork and continuous improvement philosophies. Humour was also used as a strategy by rank and file healthcare workers to attenuate the control of higher-status professionals, in this case physicians (Griffiths, 1998). Here, lower status workers, organized in multidisciplinary teams, used humour in a variety of ways to challenge team leaders. While it 
might be possible to view these dynamics in functionalist terms, understanding the workers' joking as simply 'letting off steam', Griffiths found that humour enabled employees to confront the dominant social pattern, its inconsistencies and contradictions (see also Townsend 2005, and Taylor \& Bain, 2003).

The above studies point to the importance of resistance in teams, the ways in which organizational-level controls sometimes spark team opposition, and forms that team-level dissent might take. Yet, research has rarely centered attention on how team members' constructions of difference can themselves inform employee resistance. This article examines resistance as it relates to groups with internationally diverse membership and how difference may be constructed in situated contexts. Formally sites for peer-based learning and leadership development, the management teams in this study operated in wider conditions of normative control which constructed what we identify as a normatively rigid model of the desired leader, and in so doing, constructed 'difference' as deviation from this model. Our findings illustrate how resistance can be enacted collectively in opposition to such normative control dynamics, constructing 'difference' differently, as generative rather than as 'a problem'. In exploring these findings, we posed the following research questions: in what ways and with what outcomes do international leadership development teams engage with normative controls in particular organizational settings? How is difference produced and reproduced in team members' and others' discourse in such settings? Before addressing these questions directly, the following section outlines the research site and methods for the study.

\section{Research Setting and Methods}

The data reported here are drawn from a research project involving a qualitative study of an elite, international leadership programme operating over a six-month period for senior managers of a global industry trade association. We selected this site and programme because we were seeking to understand the ways in which members from a wide range of backgrounds experience learning 
in an international, employer-led development setting. The 28 participants comprised 16 nationalities from 14 international regional offices.

\section{Research Site}

Founded in the immediate post World War II period, the research site is a longstanding international industry association with head offices in North America and in Europe. Over the past five years, the agency has undergone significant organizational change under a new chief executive. Funded by its members, large companies that operate out of many of the world's countries, the agency had mandated the chief executive to re-make the organization in the image of the most efficient and profitable of these companies. The industry was confronting a high degree of change including new technology transforming several of its functions. In this context, the chief executive's stated intentions were to pursue aggressive financial targets and to re-structure, rationalize and potentially downsize all regional offices. The organization had offices in 70 countries in every region of the world, with strong British and North American roots and was traditionally male-dominated. The current top management team was more international than in the past with two senior executives from European countries other than Britain or France. The parameters of the leadership programme according to its director included honing managerial capabilities in every region, and thus selection of programme participants targeted members from every major region of operation.

The 28 participants were divided into four teams by the programme director and senior executives who also acted as coaches. Each of the four project learning teams was assigned a prominent, short to medium term strategic initiative that the agency wished to address, on which they were expected to work for the duration of the programme. These initiatives, or problems, were company-wide in scope, and had the potential either to bring highly significant strategic benefits, or, if they were poorly planned or executed, to cause damage to the operations and reputation of the agency. Each problem was cross-functional, involving a variety of domains- 
technology, marketing, human resources, finance, accounting, infrastructure and so on. The teams were briefed on the broad scope of their assigned problem and asked to develop detailed strategic and operational plans to resolve it within the five months given to do their work. They were required to consult widely both inside the company and in the industry. The projects, however, were sometimes doubles of projects already ongoing inside the organization, making consultation with internal stakeholders a difficult and politically challenging task. As the programme director explained, this was an intentional test of participants' drive.

Team members were not given time off from their regular management responsibilities in order to complete this work. The leadership programme provided a number of workshops that covered, among other material, a set of decision-making and operational processes that the teams were instructed to use to conduct their meetings. Team members were also expected to evaluate one another's performance on an individual and ongoing basis, including with two peer forced ranking exercises, one of which took place in the first workshop of the programme, before joint project work had begun. Pressure was further increased by the intensity of the group work timetable, the presence of company-based coaches who at times also had direct decision-making power regarding participants' future careers and possible promotions, a lack of targeted time to conduct their tasks, and elements such as the forced ranking exercise.

According to the programme director, team membership was decided on the basis of maximum variation within each team on a number of dimensions - function/occupation, gender, nationality, seniority and language. Table 1 provides details of team membership. Table 2 sets out the nationalities, gender, position titles, and regular work locations of participants.

\section{Tables 1 and 2 about here}

\section{Data Collection and Analysis}

Over an initial period of 8 months, data collection included semi-structured interviews with all 24 participants remaining in the company after the programme's completion, interviews with 
several former participants and other senior managers now acting as programme coaches, ongoing interviews with the programme director, and examination of relevant company documents, for example, an end-of-cohort evaluation record. The interviews were conducted on-site in the company's two headquarters, for example during informal lunches with programme participants (see Table 3 for data collection methods). Interviews with participants took place in the weeks following programme completion, and explored all aspects of the programme experience.

Questions focused on participants' accounts of personal and team-level learning, selection and evaluation processes, impact of national backgrounds, interpersonal dynamics, peer learning and dynamics involving team members varying national backgrounds, expectations of participation, careers and future plans, and connections to regular jobs. We probed for more detailed accounts of team processes as they emerged. Interviews with the director and coaches focused on programme design, history and purposes, the relationship to corporate objectives, programme selection, evaluation and outcomes, team development and perceptions of the teams' functioning. Full verbatim transcripts of the interviews were produced professionally. Four of the interviews were not taped, either due to participant preference (two cases), or because the setting was not propitious (company cafeteria, two cases); extensive notes were taken in every case.

Additional interviews with a small number of participants were conducted several months later according to their availability, based on convenience sampling; these were useful in checking for ongoing impressions of the programme and its impact on participants' careers and work relationships. Following best practice for inductive and naturalistic inquiry, we remained open to emerging themes throughout the data collection process. We wrote memos highlighting key observations from the interviews which informed subsequent analysis and later interviews, and formed the basis of our initial interpretations of the material.

Table 3 about here 
We conducted a discursive analysis of participants' accounts of their programme experiences, and of the accounts of the programme director and the other key actors such as coaches. Our analytical approach focused on identifying and understanding common symbolic meanings constructed through participants' talk about their experiences and interactions (Prasad, 2005), in this case concentrating on the team-level of analysis. Laid over this analytical lens, we emphasized the importance of power and the ways in which discourses and practices can inform and be shaped by asymmetrical employment relations. Data analysis for the study followed a nested approach intended to embed understanding of the project team processes through members' talk within the situated conditions of broader programme discourses and practices, and the employment setting more generally.

To conduct this analysis of team members' talk, our approach followed three interrelated stages. First, we identified all references to teams and team dynamics in the interview transcripts. Interview data from the other key informants were also coded for references to the teams and team dynamics. We used first-order descriptive coding to identify these references as talk centering on team micro-processes and interactions (Locke, 2001). In this way we began to develop a sense of the within-team dynamics and climate. That groups were operating under greater conditions of normative control and tension began to emerge as a general underlying theme during this stage of analysis. For example, several participants spoke about the pressure of extremely tight deadlines, some apparently artificially imposed, and the loss through termination while the programme was still underway of certain group members (one per group) who had not performed well enough or in the ways desired. Indeed the particular prominence in many respondents' accounts of the forced ranking suggested that this practice was an important form of normalizing control; it intensified internal team competition and individualized team members. Accordingly, we conducted a more thorough analysis of programme conditions, processes and consequences highlighting several themes relating to particular expressions of organizational control, outlined in the next section. 
Second, organizing the interview transcripts into the team groupings, we looked for patterns across members' talk within each team, a type of triangulation of accounts of team dynamics where relevant. It then became possible to compare and contrast discourses across the teams, identifying emerging similarities and differences at the team level. Using constant comparison (Locke, 2001), we identified a number of dimensions on which talk about team practices varied, that we grouped into six patterns (Strauss \& Corbin, 1998). These were: team practices relating to members from non-HQ or distant locations; camaraderie/social engagement within the team; team members' plans to stay in touch on a personal level following programme completion; character of peer feedback in the team - whether it was reflective/non-reflective of programme hierarchical feedback to individuals; perceptions of teams' task-related effectiveness; and whether or how team ways of working were in compliance with decreed methods. Based on the patterns outlined above, one team emerged as a particular outlier.

To examine these variations further, we returned to the literature on teams and organizational control and resistance. This led us to focus in more detail on a number of interrelated dynamics. Extending the first pattern above (team practices relating to members from non-HQ or more distant locations), participants' talk suggested that one or two team members in each group appeared to be considered, and/or to consider themselves, as 'different' or culturally peripheral within the context of the programme. We drew on these findings to explore in more depth the meanings of difference in this setting (c.f. Mumby, 2011). While in three groups, such members appeared to have negative programme experiences, this dynamic was quite different for the 'minority' members in the outlier group.

Given this emergent finding, we then wanted to understand the extent to which teams may have reproduced normative controls evident at programme level, engaging, perhaps, in peer-based control within the teams (c.f. Barker, 1993). Our analysis sparked the question of whether, and if so how, such control might be interconnected with team members' constructions of difference. 
The 'outlier' team appeared to create conditions, not of control, but of a kind of perceived freedom and solidarity for its members. While the other three teams, to varying degrees and in different ways, appeared to reproduce the controls in the programme, this one team exhibited a different dynamic. This analysis led us to a third conceptual theme, relating to the identification of teamlevel resistance. We asked how and why this particular team engaged in oppositional practices, in contrast with the other three teams, and with what effects? The following sections discuss our findings concerning these questions, and then elaborate a more detailed exploration of two teams, one 'typical' and one 'outlier'.

\section{Control and Constructions of Difference}

Our analysis of context found that a considerable degree of normative control/identity regulatory practices characterized the programme and the way it was experienced by participants. In particular, we found that a Western, white, individualistic and masculine norm of leadership was prescribed and reinforced through a range of discursive programme practices, set out below (see also Gagnon \& Collinson, 2014). These practices were in tension with formal managerial statements that overtly 'valued diversity' and a 'global orientation' as central programme aims. Based on the themes delineated below, we theorize this assertion of a normative leader model as a form of control expressed in the context of the programme. Several disciplinary practices that reproduced this particular model are outlined here; they are further elaborated in team members' talk, the subject of our next findings section. First, selection and evaluation processes were important in reinforcing this norm. Participants were compelled to join the programme, and could not securely decline, as one participant who asked to defer due to family responsibilities put it: "I said, ah, I didn't apply for it... so I felt like, you know, somehow you're privileged but on the other hand, you were not asked for your opinion” (Asst Director, Switzerland, M; from Team 3). The implicit message was that participants should simply 'tough it out'. 
Second, the programme created a highly pressurized environment, and placed value on risk and the ability to perform in high-pressure settings at short notice. There was little or no time off from regular work to enable participation. A forced peer ranking process carried severe consequences, including termination, for those ranking lowest. The use of internal team coaches and sponsors created an acutely politicized environment. Participants had heightened visibility given the seniorlevel executives acting in these coaching roles, rendering the stakes of failure very high for one's future career. As one senior manager explained with respect to the forced ranking exercise in particular:

I think there were two different elements of people being unsettled by that process. One was the personal one that says, 'I feel uncomfortable telling somebody that they are bad or they're doing something wrong,' or equally, 'I feel uncomfortable if people are telling me that I'm doing things badly.' The other was what I would call the fear factor, 'hey, if I'm getting feedback that, say, I'm not good in this area, is that going to get to (the CEO and senior management), and is that going to reflect on my future career?' There was a real fear factor as well. And the different status and grades came in, because the more junior people were more fearful. (Director, Britain, M; from Team 1)

Further, the programme was not seen as a 'transparent' exercise in development, re-affirming the general perception that ultimately, it was more akin to a test of who might fit the narrow model of leader that the firm sought, for example through toughness and embracing risk:

Another frustration has been that when positions have become vacant and people internally have applied for those vacancies, alumni of the programme, the general impression is that they are not a shoe-in for these positions. This is the rub, if you will. You've got an internal development programme but all the new jobs are going to external people. (Manager, Spain, M; from Team 4)

Third, participants who spoke less fluent English, and whose regular work location was a local or regional office more geographically distant from headquarters, often felt that they were treated as of lower status in the currency of the programme. These 'different' or minority participants had less cultural capital than the dominant Anglo-North American members. Participants were expected to have previous social and political connections with peers and superiors and to display 'speed', 'initiative', decisiveness and directness in communication. This Team 2 member highlighted the role of internal coaches in contributing to the sense of unease felt by some: 
The feedback from the coach was very difficult...I was left going through my mental processes, very shaky, very sensitive; it can destroy people. They should not have just anyone as a coach, it should not be taken 'a la légère'... (Manager, France, F, from Team 2)

Continuing this theme, participants used the term 'Anglo-Saxon' when referring to the dominant macro-cultural group, even though this group was not particularly British and the term seemed to encompass people originating from different parts of Western Europe (if their English was fluent), as well as from North America and Australia. This term was also used by executives, coaches and others who were not current programme participants. We inferred that 'Anglo-Saxon' also had a racial connotation in that it was often used in juxtaposition to 'Latin' or 'Asian'. There appeared, however, to be one non-white person meeting the Anglo-Saxon delineation, a man of British-Chinese origin, now living in Canada.

Fourth, gender was significant in the construction of the norm. If one was both a woman and a minority according to the above description, this tended to constitute a double deficit or 'double strangeness' (Acker, 2008). Women were a sharply defined demographic minority, comprising only 8 of the 28 original participants. Their 'difference' was reinforced in the programme through their equal distribution as tokens across the four project teams.

In sum, a universalist, non-minority category in the context of this leadership programme could be understood as English-speaking, centrally located, male, well-connected and white. Difference therefore took on intersecting forms in the programme's discourse and practices in which certain interwoven identities were privileged, whilst other mutually-reinforcing differences were subordinated.

Drawing on this analysis, we made two preliminary observations. First, teams' constructions of difference varied in important ways. Teams 1 and 4 appeared to have one person who stood out as a 'minority' member following the above criteria, who felt excluded and for whom this was corroborated in other group members' accounts. For example, group colleagues referred to this person as a 'problem', a non-contributor, and a poor performer. Team 2 similarly constructed 
difference around one 'minority' or 'different' person due to her home location, ethnicity and gender, about whom several members spoke at some length in their accounts. However, she was not singled out as being a 'problem' but rather as someone whose contribution was highly valued by team members. Team 2 constructed a second minority member whose culture and language were often mentioned, distinguishing it from the norm, but who was also the focus of several positive comments from teammates. For example, he had been responsible for relieving the harsh tone of programme activities on several occasions. Team 3 members did not identify a particular person emerging in the accounts as 'different'; rather several people seemed to fit this category in the group.

Second, the accounts of Team 2 members revealed group engagement in collective oppositional practices to the decreed ways of working, not present in the other three teams. This consisted in a collective refusal to use the programme-ordained group working tools, neither using nor taking to heart the forced ranking as a way of measuring team members, and forming close group bonds through cutting humour often directed against the programme and its demands. In other teams, individual members variably expressed doubt and mistrust of programme processes, however this did not translate into group-level opposition. Rather, despite individual-level complaints, the other teams tended to reproduce programme level normative controls. These dynamics are detailed in the following sections.

\section{Contrasting Team Processes: Team Control vs Oppositional Practice}

To explore contrasting practices within the three 'normal' or normalized teams and the one resistant team, we first describe in more detail one of the three teams exhibiting the 'norm' of team processes (Team 1), and second, the team which we came to understand as more oppositional (Team 2). The argument advanced is not that there were no controlling practices within the resistant team, and no resistant practices in the controlling teams. Rather, ample illustrations of both occurred in all teams. However, Team 2 clearly stood out as more resistant, and we aimed to 
examine in detail how and why this was manifest, and the implications, both theoretical and empirical.

\section{Teams 1, 3 \& 4-Team discipline through individuation}

Team processes were generally experienced as stressful and lacking in affiliation or camaraderie. Our analysis draws out the link between this apparent reality and the implicit and explicit normative control. Along with Teams 3 and 4, Team 1 displayed a compliance with all programme norms and directives, although this was at times reluctant. All these teams had fraught interpersonal relations and did not show team-level camaraderie. Further, there was little crediting of the team as a source of members' learning or performance. Identity-related issues of rank and status were prominent, and there was a strong tendency to single out 'problem people' who were 'outside the norm'. These teams thus constructed 'difference' as different from the required norm, and in this way, engaged in the individuating of team members who were deemed to be different: a process which functioned as a form of team-level discipline reproducing broader controls. For these teams, difference was a problem to be neutralized.

\section{Creating difference through singling out 'problem' people. Several group members} mentioned an assistant manager from central Europe who experienced difficulties starting in the early stages of team working. The manager`s own account emphasizes feelings of both exclusion and difference given her a) geographic distance from the two corporate headquarters, b) language issues, c) gender, and d) relatively junior status. "We had a multi-nationality group, one person who had a lot of issues, and a language barrier too, so in part, it was a matter of understanding her culture, but this was difficult" said one member, noting that such problems were exacerbated in this high pressure environment (Regional Mngr,. Mexico, M). Others mentioned that the manager took team feedback badly, increasing anxiety within the group, yet there was little sense that this minority member was assisted by the group in any way. For example, the other woman in the group first expressed the 'difference' of this person referring to culture and saying, "she was 
dictatorial", but perhaps "just trying to prove herself", but also "in the wrong" and unwilling to change (Mngr., Britain/West Indies, F). Asked if she felt an understanding as the only other woman, she replied,

No. I tried - that is a good question, because I wanted to. There were only two women but we initially did not have an affinity based on gender, which I looked for, because I wanted to find a way to bring her back into the fold. Because she initially, well, whether she had excluded herself or we had excluded her, in the first few weeks, it's hard to say. But she was on the outside of the team.

Other members' accounts referred to the central European manager as stressed and intimidated.

The team was unable to improve this state of affairs, and may not have tried. The manager herself

felt condescended to:

'You will see that you will gain the most of all these people,' the coach told me, 'they are willing to help you with everything,' and well, it surprised me. Why do they think that I need help? Maybe they need help more, because I have my brain ... so I am told I am the youngest, the least experienced, and I need help. This is not true. I wanted to show them that, listen guys, this is not that way. I can compete with you very easily. But I was not given the opportunity to position myself; I was from a field office, people made assumptions about me, and there was no time to establish myself. (Asst. Mngr., Slovakia $\left.{ }^{i}, F\right)$

Her account suggests that the team was unwilling to accommodate and listen, which appeared to sap her confidence. She was taken aback to be defined as 'not good': "It was repeatedly proclaimed that there are no ranks, forget the ranks, the hierarchy, the levels, but it was still in those people, and at the beginning, for me it was a huge, absolutely huge problem," she added.

Certain members were similarly singled out and identified as 'other' in Teams 3 and 4. A senior man from a middle-eastern country described being constructed as lower status on Team 4. "We had one casualty," said a British member in reference to the person; "he stayed with the group, but we lost him." Another said this person was very intelligent and capable, but had a "totally different logic sense; his thinking is different." The team did not confront this 'difference' but rather seemed to develop a "we vs. he" dynamic; as one member said, "We had some discussions with him but didn't go into 'analyzing' the difference because it was going to be counter-productive to what we were supposed to achieve." 
Reluctant compliance with forced ranking. Several team members referred to the forced ranking as a point of tension especially for minority members. "There was one person who took (the ranking exercises) very personally and badly" (Asst. director, Canada, M). This member said he "gave it pretty good" himself, referring to the blunt peer feedback encouraged in the ranking, adding that the team was expected to give negative feedback, and did so: "This was the whole atmosphere, be decisive, be very direct - they were promoting that." Still, the group as a whole found the peer feedback difficult: "People were very unsettled by the whole process... People dwelled on (their individual feedback) for weeks... I know someone who couldn't function properly because of the feedback he got" (Mngr., Britain/West Indies, F). The ranking process intensified insecurities within most of the teams. Ironically, the teams also did an exercise called 'SARA' (shock, anger, retreat, acceptance), designed to learn the stages of grief in order to mitigate the shock of receiving negative feedback in the rankings. Those who consistently found the ranking most difficult were the non-'Anglo-Saxons' in the team. While there was little support for the exercise, nor for 'the system' or programme approach in general, Teams 1, 3 and 4 complied and completed the activities. Moreover the more dominant team members tended to see these methods as effective. Asked whether the forced ranking is effective, one Canadian man replied:

I think so. It forces people to look at themselves in the mirror, and to either change or be changed. I'm being very blunt here. This puts it out on the table and forces the issue, when there are issues. And when there aren't, it is positive reinforcement and the behaviours that are the ones, well, sought by the organization, then are just repeated, and done better... (Director, Canada, M).

Lack of camaraderie. There were few mentions of camaraderie, fun or humour in Teams 1, 3 and 4. Rather, members confirmed that group work was difficult and involved considerable stress. "It was very challenging to work out the differences between people" (Regional mngr., Mexico, M). He stressed language problems, saying that the group had "a lot of bumps on the way. (The project) was hard work, I can't say I enjoyed it, it was not 'fun'.” Nor did group members make 
plans to stay in touch post-programme: "For our group, we lost track of one another quite quickly" (Asst. director, Canada, M); "You're so tired that you want to forget it!" (Regional mngr., Mexico, M). He attributed the group's problems to the fact that some were working hard for their own recognition, as fostered by the programme:

In part it had to do with people driven by what they thought - and what they were told - they were going to get out of this. So this affected our attitude and way of handling difficult moments; there was some tension and some disagreement.

Members of Team 1 did not credit the team with contributing to their own learning. Rather, the group dynamics involved "interactions between members that were less desirable -- issues were basically pushed aside and not addressed" (Director, Canada, M).

Rank issues. Members often gave salience to rank and status as one reason for the poor relationships. The regional manager from Mexico explained that rank issues impeded the group's ability to work together, 'unfortunately we have people who think, 'I'm a director' and they will think of themselves that way no matter where they are.” In the central European member's account, rank was the most significant symbolic barrier to inclusion. She found that in order to benefit from the programme, she was compelled to resist the pressure of the team to take her 'proper' place as the most junior member. Her learning was in spite of the team, rather than because of it.

Little evidence of team level opposition. Although several members expressed scepticism of programme goals, for Teams 1, 3, and 4 this theme did not translate into team resistance. Team dynamics appeared to push members apart, rather than form a collective which we found was related to team-level resistance (as in Team 2). In Team 1, members' experience of collective 'synergy' was negative or neutral at best. Team work was instead 'individuating', related primarily to the personal ambition of respondents, and to broader programme-imposed controls. Pressure mitigated teams' ability to build relations of trust and mutual support; conditions of normative control exacerbated these tendencies. The default position of these teams was to reproduce the 
inequality embedded in the programme, reinforcing status differences and divisions, and thus exclusion and competition. Within Team 1 the result was a general sense of uncertainty and insecurity.

\section{Team 2 - The Resistant Team}

Team 2's practices were distinct from the other three groups in a number of ways. Members expressed much more oppositional and sceptical attitudes compared with those in the other three groups. Dissent also took on a more collective form, informed by an iterative process of joint working and group sense-making. In Team 2, opposition to programme level control went beyond individual complaints and involved collective subverting of programme requirements, speaking out and 'making fun' of hierarchical decrees, and more profoundly, not creating 'problem people' within the team. This team reduced status differences, unlike the other three teams who tended to reproduce and reinforce them. They created a sense of group 'inclusion' of difference that both reflected and reinforced their opposition, expressed in terms of surfacing programme inconsistencies and contradictions. In this sense, inclusion as acceptance and activation of differences on one hand, and resistance on the other, were co-constituted and co-constituting.

With respect to their heterogeneity in particular, Team 2's reduction (or non-reproduction) of status differences was an important form of resistance to the programme's normative, identityregulating control. Our findings suggest that Team 2's resistance a) responded to normative control for heterogeneous groups, b) was informed by reconstructions of intersecting differences, c) had consequences for both individual and team learning, and d) operated simultaneously as inclusive practices. The following discussion outlines various ways that Team 2 resisted many of the central tenets of this leadership programme. It focuses in particular on: the rejection of ordained team process tools; anti-hierarchy practices; humour and making fun, and developing positive constructions of difference. Finally, this section also explores the generative outcomes of Team 2's oppositional practices. 
Rejection of ordained team process tools. First, Team 2 did not use the group decision-making and procedural tools given to them in the workshop sessions. Group members' accounts imply that a rejection of these tools was a purposeful choice; the tools were seen as over-simplified and stifling freedom and discretion. As one member explains:

We were given some tools to organize our meetings, very formal ones, we never used them.... All these tools, defining who was in the leadership role, and so on - they were just trying to apply some easy rules, like 'the seven words or seven rules, the golden rules, to successful team working.' No, we rejected these, and we managed to behave quite adequately. We did not choose to focus too much on the tools... Instead we were able to work intuitively, applying common sense, and it worked very well. (Director, France, M)

Another reported with some irony: "They gave us the (goal-setting and performance rating tool) GRIP ${ }^{\text {ii }}$ but our team wasn't very good at this; we didn't conform” (Manager, France, F). Put simply, "We did not use the tools," but preferred to "make our own decisions about what was useful and what was not... The way the group behaved, we left that to the group to imagine it" (Director, France, M). This was mentioned in each team member's interview comments.

They gave us a methodology, a tool about how we should structure our meetings, how to structure the project, they said 'here's the tools you should follow.' And we just abandoned those; we did not even try to use them. We just used our own natural experiences to guide the group. But that was looked upon as arrogance. So in the beginning, they all pictured us as being the group that would fail. ... And at the end of the day I would say, and I'm biased of course, but I would say that our project scored the highest. (Director, Canada, M)

Instead of following prescribed procedures, the team also developed its own ways of dealing with disagreements.

We did this one-on-one; we avoided group therapy... we're not ex-alcoholics. There are other ways to do this, respecting also the sensibility of everybody. So we used the group to work, to have fun, but coaching and debriefing was always one-to-one. Or maybe three people. And it proved to be very efficient. Because it respects people...you don't have to discuss this publicly. It's much more powerful. And it's not the group speaking to someone, ganging up... (Director, France, M)

Anti-hierarchy practices. A second way in which this group resisted managerial control was through non-hierarchizing practices that reduced rather than reproduced status differences. The forced ranking exercise proved to be divisive and controversial in all groups, but all other groups 
complied. In contrast, Team 2 remained highly skeptical of this exercise. As one member commented in relation to forced ranking:

This was difficult for me. To do this after a very short period (of knowing one another) is difficult; it's as though only the first impressions are important, so all you get is an understanding of the first impression that you make. But I'd rather not be saying things about people that I don't know, I've known them only a few days. I think everyone in our team felt that way. They should give you more time on that. We had 30 minutes to rank 7 people. It was much too early in the programme and much too short a time was allocated to it. (Senior counsel, Britain/Hong Kong, M)

Variations of this sentiment were echoed by other Team 2 members; their response in practice was simply to collectively de-value the process. "These ratings were not useful in my team," said another member, "We needed everyone in order to do the job. We couldn't just drop people or say they were lower.”(Mngr., France, F) No members of other teams mentioned downplaying or setting aside the forced ranking exercise. Rather, as the accounts in the previous section show, the exercise had a considerable negative influence on people's self-conceptions and on group climate and relationships. In contrast, Team 2 countered the surveillance techniques embedded in the forced ranking. They did not differentiate team members' value in ways encouraged by the company's leadership- either through using the forced ranking or in other inter-subjective ways. Rather, they remained committed to enhancing the teams' sense of group cohesion and equality.

Humour and making fun. Team 2 members repeatedly highlighted how humour and fun were vital factors strengthening the sense of group inclusion, identity and resistance. References in the other three teams to such joking dynamics were largely or completely absent. "We had high enjoyment I would say," said one Team 2 member, "We laughed a lot, we were coping (by using) incredible jokes" (Comptroller, South Africa, F). These jokes were often at the expense of the programme, its jargon, values and exercises. Several members mentioned the jokes offered by one non-English first-language member. He shared proverbs from his country with the group, whenever these fitted the situation, for example:

...during hard times. He'd use these - had us laughing all the time...He'd bring all these proverbs to us and we'd laugh and laugh. One of the company values says something about 'going 
over the top'; he couldn't understand this. Also 'walk the talk' - he had a lot of fun with that one. Imagine for people who come from other cultures, it's difficult to comprehend - 'what is that??' he'd say, 'it's ridiculous.' It doesn't mean anything in his language, and is probably nonsense altogether, he would say. He shared a lot, kept us going, we laughed. (Comptroller, South Africa, F).

This member also gave literal translations of some of the jargon used in the workshops. For example, a workshop leader used the term "bleeding edge" as a play on words of 'leading edge', to connote the fastest, most decisive action possible on the part of managers facing tough issues, to which participants should aspire. The team member said this simply could not be translated in his language:

'Bleeding edge'- what kind of phrase is that?' he'd say. What caused even more hilarity for us was that (this member) was then singled out in a fairly serious way by the programme director who said, 'X, I can see you've got a lot to say.' And the person answered by immediately changing his remarks to reflect the substance of the session. It was hilarious...(our group members) had trouble containing themselves (Comptroller, South Africa, F).

Others' accounts of this incident suggest that it was clear to all that the team was mocking some of the primary tenets of the programme, and further, that openly doing so in this way was risky and well outside the norm. The later termination of one senior participant (from Team 3) following her open criticism during a programme workshop and the company's strategic vision in which it was grounded, bore out this assessment. Labelled 'belligerent' by the programme director during a research interview, her firing followed a session involving the programme director, coaches and other senior executives in which participants were assessed and rated on their future leadership potential. Those receiving poor ratings from these executives, using the forced rankings as well as coaches' and sponsors' assessments as the basis for evaluation, were terminated. Such meetings occurred twice during the period of the programme - once immediately following the second workshop, and once at the end of the taught section of the programme.

Team 2 used humour as a way to question the dominant messages and content of the programme. They literally made fun of prime programme values and messages emphasizing speed, efficiency, and hyper-task orientation. Linked to the use of humour was the presence of 
more socializing, less apparent in the other teams. In this sense, Team 2 enacted their own group values and preferences, in opposition to those projected in the programme. This team's humour allowed the members, when set against the unequal power of the different participants, to construct their relations as collegial and egalitarian rather than competitive and hierarchical. Team 2 members' debunking of the programme through questioning humour reflected and reinforced their strong social bonds. The sense of group inclusiveness informed their willingness and confidence to resist programme stipulations. Through the most 'peripheral' member's cutting and satirical humour, drawing on his own language and the ways in which programme jargon was untranslatable into his language, the team asserted understandings distinct to that culture, and humour more generally as a source of divergent thinking. Their resistance was thus linked directly to their diversity. The team surfaced what Foldy et al. (2009) have called cultural 'undiscussables' which usually stay hidden and/or unacknowledged, instead having fun with cultural variety and using it in ways that countered programme decrees.

Further, the team engaged in collective, incisive critique of the programme, exposing and sometimes belittling its aims. This is significant, we argue, given the embeddedness within the organization of several team members. We would thus expect complicity or at least tolerance; instead, the sense of solidarity as a micro-collective gave individuals license to speak out. At times the team's critique took the form of direct parodying of control processes, for example, in relation to the forced ranking exercise.

Developing Positive Constructions of Difference. Much less evident in the other three groups, Team 2 members interpreted differences in highly positive and inclusive ways. They bridged cultural and status differences which were a function of this context, key factors that differentiated team members and reproduced control in other teams. "Cultural differences did not become a barrier for us... Ours was in fact the most culturally-mixed team, but from the beginning we recognized one another's strengths, we let one another get on with it" (Senior 
counsel, Britain/Hong Kong, M). The member whose normal work location was the most distant from headquarters both geographically and on standard measures of 'national' cultural difference, reported that he "did not feel a cultural shock" in his team, although the programme as a whole "had a very Anglo-Saxon style" (Mngr., China, M). While this member did say that the "AngloSaxons" in his group would sometimes "dominate" discussions, his sense of inclusion lends support to the statements of other members concerning the collegial nature of their group relations. At the same time, this person was open in his criticisms of the programme: "I found some things useful, others not," he said. Backing this up, three team members said their "biggest learnings" from the whole programme were from their team members and the collaboration they achieved in the team.

Generative team outcomes. Team 2's success in their tasks relative to the other groups speaks to a paradox found elsewhere in the literature: resistance can produce generative outcomes that are not necessarily inconsistent with the needs of the employer (Thomas and Davies, 2005a).

"Everybody might think they are the best, but we were. We were good," said one member (Manager, France, F). "I think we did extremely well; the outcome was probably the most successful of all the four," said another (Director, Canada, M).

The ace for us was the risk we took in devising a system and going out to the industry; we had a meeting in 3 major cities and pulled in all the key stakeholders and presented to them, what we thought was the solution... It was risky. But we got a buy-in. We also sold the idea to the Director General, we laid posters across the room with quotes from people, the biggest players, saying this is the way forward... Our project scored the highest... That's what I was told. But we were also called the most 'arrogant'. (Director, Canada, M)

In summary, Team 2's oppositional stance in response to programme controls was shaped by their inclusiveness and cohesion. Team members were less competitive and anxious as a group; they conformed and complied less. These outcomes were achieved through deconstructing status differences, in which power imbalances were not enacted, showing a collective commitment to equity, and the valuing of cultural differences. The findings suggest that the impact of this 
resistance, and its lack in other groups, links to this team's generative outcomes both collectively, and individually by the two 'minority' group members. The informal space created by Team 2 in opposition to programme controls, in which participants were out of view of the programme`s disciplinary 'gaze' with its requirement to perform in certain ways, arguably allowed this development to occur. Elsewhere, 'minority' members did not exhibit the same confidence in their work or learning, but were instead bridled by the rigid conditions of the programme and their teams, working mainly, perhaps, to survive. Taken together, Team 2's oppositional and inclusive practices were co-constituting.

\section{Discussion}

This study has uncovered a number of ways that constructions of difference can shape resistance practices. Drawing on an inductive study of an elite global leadership programme, the paper has explored how difference is produced and reproduced in international team members' talk. Informed by a social constructionist/discourse-based approach, the paper reveals how talk in Teams 1, 3 and 4 typically constructed difference as a problem: 'difference' placed people outside of the discursively constructed programme norm. For Team 2, by contrast, difference was constructed as a productive resource that provided an effective way for team members to connect with each other and to resist the hierarchies and controlling practices of the programme. Here, difference was framed and constructed around inclusiveness. In comparison to Teams 1, 3 and 4 who 'othered' and marginalized certain members, Team 2 did not stigmatize any of its members, (re)constructing difference as positive. This analysis suggests that conditions of normative control may also give rise to forms of resistance that draw directly upon, and indeed co-constitute, members' collective sensibility, as a community of equals. For the other three teams, by contrast, such results were not possible because difference was collectively constructed as grounds for division and exclusion. This in turn was consistent with programme-level normative controls that 
encouraged a narrow definition of the meaning of success and what it meant to be a successful leader in this organization.

The article raises a number of important issues that have significant, interrelated implications for the analysis of organizational resistance. First, it locates issues of control and resistance, power and agency, within the context of team processes, focusing on the under-explored issue of team resistance, particularly within managerial hierarchies. Normative control in the programme was pursued in part through team practices and accomplished, to a degree, through individualizing dynamics that led to the othering of certain team members and construction of negative internal differences. Although in conditions of normative control teams can target and discipline their members, the study demonstrates that such processes are by no means inevitable, and team discipline is not all-determining. This was illustrated by the one team which, through its oppositional discursive practices, articulated divergent views and established a degree of group independence and autonomy, absent in the other teams.

Second, this focus on team resistance uncovers under-explored analytical links between contemporary forms of control, dissent and difference. Our study found that expressions of difference may run counter to the homogenizing impact of the prevailing regime, and form an important basis of resistance. It suggests that team members can collectively draw on their cultural difference in order to resist normative controls, and in so doing, co-create an inclusive microenvironment. In Team 2, processes of resistance and inclusion operated simultaneously and were mutually-reinforcing. Importantly, their dissent occurred through non-individualization. Team 2 members did not compete with one another as the programme stipulated they should.

Accordingly, we label this collective opposition, which valued internal differences and developed the sense of group-based distinctiveness, as an expression of 'resistance through difference'. Research by Collinson $(1994,2000)$ identified two distinct forms of workplace opposition: 'resistance through distance' and 'resistance through persistence'. In 'resistance 
through distance' employees are primarily concerned to differentiate themselves psychologically, culturally and spatially from the organization and from those in power. In so doing they 'distance' themselves and deny responsibility for organizational decision making. By contrast, in 'resistance through persistence' employees seek to render managerial decisions more visible, transparent and accountable. To successfully challenge managerial decision making, this demand for more information and explanation has to be particularly persistent, resilient and tenacious.

In the study reported here, Team 2 re-interpreted and challenged many of the employer-led leadership programme's primary stipulations, and in so doing, ironically, performed more effectively. In this sense, they resisted by: valuing and bridging difference(s); rejecting ordained team process tools; engaging in anti-hierarchical practices; using humour through asserting language and culture, juxtaposing cultures, incisive critique, and parodying control processes. ${ }^{\text {iii }}$ Accordingly, their resistance through difference occurs through collective processes that reject broader normative controls and draw directly on difference. Team 2 members simultaneously critiqued the programme and enhanced their sense of collectivism, juxtaposing their own differences with its Anglo American-centric assumptions and contradictions. Resistance opposed the programme's imposition of Western principles, identities and values, whilst simultaneously strengthening group bonds. In this way, resistance co-constitutes inclusion and vice versa. Indeed in conditions where control tends to differentiate and individualize, resistance can be inclusion and inclusion can be resistance.

\section{Implications for Future Research}

Our emphasis on 'resistance through difference' and on the co-constitution of dissent and inclusion is suggestive of a number of lines of inquiry for future research. First, our analysis underlines that, from a power perspective, it is rarely helpful to see teams simply as socially differentiated. Conditions of control are critically important to examine, to understand how differences are constructed in situ and reproduced in particular practices. Control can reinforce 
status differences through privileging certain selves over others. The majority of teams in this study conformed to such controls, not merely 'failing to get along' in a decontextualized sense (relating only to some notion of a priori differences in culture, language and race/ethnicity). Rather, difference was given meaning by the context and the power imbalances that were reproduced as part of the programme's normalizing and homogenizing practices. Accordingly, future research might explore other conditions and contexts of such control. Relatedly, research from a power perspective could also further explore the interrelations between resistance and subjectivities. For example, resistance to normative control is typically informed by the assertion of counter-subjectivities. As in the case of Team 2, these may be collective and collegial, lighthearted and emotional/affective. Rather than othering, marginalizing, racializing, and/or excluding, oppositional subjectivities and practices can resist status differences and equalize power by reconstructing difference as generative and productive. In the inclusive/resistant team, members constructed difference differently, and consequently, they performed better.

Second, we suggest that there may be a dialectical relationship between difference and resistance: a theme which could also benefit from future analysis. Our study focuses primarily on how difference shapes dissent, but it may also be the case that resistance impacts on difference, for example in relation to identity confirmation. This in turn raises additional issues about the meanings of 'difference' as a manifestation of both resistance and of identity construction/ confirmation (see also Mumby, 2011, Ashcraft, 2011). Indeed future research could examine further ways that multiple and intersecting constructed differences can spark resistance in organizations, as well as exploring their important conditions and consequences (Putnam, Jahn \& Baker, $\left.2011^{\mathrm{iv}}\right)$.

While we note the limitations of our study arising from its design as a single case study, we hope that the foregoing suggestions help to underline our theoretical insights that may guide further research on the key notion developed here, 'resistance through distance.' Indeed as 
globalized processes expand and non-Western and non-US cultures become more significant in international economic and political activity, difference as a basis for resistance to western hegemony in management practice could well become more prevalent. Oppositional practices such as 'resistance through difference' may thus become a more significant focus for future research on international organizational dynamics.

\section{Implications for Practice}

Increasing internationalization of workforces suggests that new, or to date unexplored, forms of workplace control and resistance may have important practical as well as theoretical implications. Our research suggests that leadership development programmes could be redesigned in ways that seek to learn from, rather than suppress both 'difference' and workplace resistance. Future research can also examine possible generative effects of resistance. Associated with Team 2 was a greater apparent degree of learning and divergent thinking, evident in their humour, and in outcomes of their work. Their resistance enabled them to learn from this restrictive programme. Divergent voices have been linked in previous research to learning (Edmondson, 2003; Heimer \& Vince, 1998). Our study shows that divergent voices may also be dissenting, that is, not merely 'creative', but also oppositional.

This analysis also raises questions about the practical outcomes of resistance. By one analysis, Team 2's resisting practice might be read as cynical, with the ironic outcome of aiding the employer's agenda of extracting high quality work from the leader programme. More subtly, it may be suggestive of Kondo’s (1990) theorizing of resistance as (sometimes) contradictory, simultaneously legitimizing and challenging dominant organizational discourses. Kondo argued that individuals frequently consent, cope, and resist simultaneously and in complex, ambiguous ways. Team 2 members were not so much enacting practices and producing results that inadvertently supported the organization's aims. Rather, they were asserting their diverse and autonomous selves, and the result was a form of resistance (through difference) rarely seen in the 
literature. This had the generative consequence not only of improving team members' personal learning and quality of experience, but also of thwarting the organization's definition of what constitutes an effective leader or who could be successful. Thus, their dissent was productive in the sense of successfully resisting this definition, a form of control, and asserting that 'success' could come from oppositional selves. That only collective resistance made this difference suggests the ongoing power of organizational controls, and thus, the continuing importance of studying contemporary resistance in its many diverse, shifting, creative and paradoxical forms.

\section{References}

Acker,J. (2008) Helpful men and feminist support: More than double strangeness. Gender, Work and Organization. 15: 288-293.

Ahonen,P., Tienari,J., Merilainen,S. \& Pullen,A. (2014) Hidden contexts and invisible power relations: A Foucauldian reading of diversity research. Human Relations, 67(3): 263-286.

Ailon-Souday,G. \& Kunda,G. (2003) Local selves of global workers: The social construction of national identity in the face of organizational globalization. Organization Studies, 24: 1073-1096.

Ailon,G. \& Kunda,G. (2009) The one-company approach': Transnationalism in an Israeli Palestinian subsidiary of a multinational corporation. Organization Studies, 30(7): 693-712.

Alcoff,L.M. (2006) Visible identities: Race, gender, and the self. Oxford: Oxford University Press.

Ashcraft,K.L. (2005) Resistance through consent? Occupational identity, organizational form, and the maintenance of masculinity among commercial airline pilots. Management Communications Quarterly, 19(1): 67-91.

Ashcraft,K.L. (2011) Knowing work through the communication of difference: A revised agenda for difference studies. In Mumby,D. (ed), Reframing difference in organizational communication studies: Research, pedagogy, practice. London: Sage, pp. 3-30.

Bell,E.L. \& Nkomo,S. (2001) Our separate ways: Black and white women and the struggle for professional identity. Boston: Harvard Business Press.

Barker,J.R. (1993) Tightening the iron cage: Concertive control in self-managing teams. Administrative Science Quarterly, 38: 408-437.

Barley,S.R. \& Kunda,G. (1992) Design and devotion: Surges of rational and normative ideologies of control in managerial discourse. Administrative Science Quarterly, 37: 363-399.

Brannen,M.Y. (2009) When Mickey loses face: Recontextualization, semantic fit, and the semiotics of foreignness. Academy of Management Review, 29: 593-616.

Burawoy,M. (1985) The politics of production. London: Verso. 
Chevrier,S. (2003) Cross-cultural management in multinational project groups. Journal of World Business, 38(2): 141-149

Coch,L. \& French,J.R.P. (1948) Overcoming resistance to change. Human Relations 1: 512-532. Cockburn,C. (1983) Brothers: Male dominance and technological change. London: Pluto Press. Collinson,D. (1992) Managing the shop floor: Subjectivity, masculinity and workplace culture, Berlin: Walter de Gruyter.

Collinson,D.L. (1994) Strategies of resistance: Power, knowledge and subjectivity in the workplace, in J. Jermier, D. Knights and W. Nord (eds.) Resistance and power in organizations. London: Routledge, 25-68; re-published (2000) Work and society: A Reader, Grint,K. (ed), Cambridge: Polity Press, 163-198.

Collinson,D.L. (2003) Identities and insecurities: Selves at work. Organization, 10: 527-547.

Collinson,D.L .(2011) Critical Leadership Studies. In: Bryman, A., Collinson, D.L., Grint, K., Jackson, B. and Uhl Bien, M. (eds) The Sage handbook of leadership. London: Sage, 179-192.

Courpasson,D. \& Vallas,S. (eds) (2016) The sage handbook of resistance. London: Sage.

Courpasson,D., Dany,F. \& Clegg,S. (2012) Resisters at work: Generating productive resistance in the workplace. Organization Science, 23(3): 801-819.

Deetz,S. (1995). Transforming communication, transforming business: Building responsive and responsible workplaces. Cresskill, NJ: Hampton Press.

Edmondson,A. (2003) Speaking up in the operating room: How team leaders promote learning in interdisciplinary action teams. Journal of Management Studies, 40(6): 1419-1452.

Edwards,R. (1979) Contested terrain. London: Heinemann.

Ezzamel,M. \& Willmott,H. (1998) Accounting for teamwork: A critical study of group-based systems of organizational control, Administrative Science Quarterly, 43(2): 358-397.

Fleming,P. \& Spicer,A. (2003) Working at a cynical distance: Implications for power, subjectivity and resistance. Organization, 10(1): 157-179.

Foldy,E.G., Rivard,P. \& Buckley,T.R. (2009) Power, safety and learning in racially diverse groups. Academy of Management Learning and Education, 8(1): 25-41.

Gagnon,S. \& Collinson,D. (2014) Rethinking global leadership development programs: The interrelated significance of power, context and identity. Organization Studies, 35, 645-670.

Giacalone,R.A. and Greenberg,J. (1997) Antisocial behaviour in organizations. Thousand Oaks, CA: Sage.

Giddens,A. (1979) Central problems in social theory. Cambridge: Polity Press.

Goffman,E. (1956)The Presentation of Self in Everyday Life. Edinburgh: University of Edinburgh.

Graham,L. (1995) On the line at Subaru-Isuzu. Ithaca, NY: ILR Press.

Griffiths,L.(1998) Humour as resistance to professional dominance in community mental health teams, Sociology of Health and Illness, 20(6): 874-895.

Heimer,C. \& Vince,R. (1998) Sustainable learning and change in international teams: From imperceptible behaviour to rigorous practice. Leadership \& Organization Development Journal, 19(2): 83-88. 
Hewlin,P.F. (2003) And the award for best actor goes to...: Facades of conformity in organizational settings, Academy of Management Review, 28(4): 633-642.

Hodson,R. (1995) 'Worker resistance: An underdeveloped concept in the sociology of work' Economic and Industrial Democracy, 16: 79-110.

Jermier,J., Knights,D. \& Nord,W. (1994). Resistance and power in organizations, London: Routledge.

Kondo,D.K. (1990) Crafting selves: Power, gender and discourses of identity in a Japanese workplace. Chicago: University of Chicago Press.

Konrad,A. (2003) Special issue introduction: Defining the domain of workplace diversity scholarship. Group and Organization Management, 28(1): 4-17.

Kotter,J.P. \& Schlesinger,L.A. (1979) Choosing strategies for change. Harvard Business Review, 57: 106-114.

Locke,K. (2001) Grounded theory in management research. Thousand Oaks, CA: Sage.

Matveev,A. \& Nelson,P. (2004) Cross cultural communication competence and multicultural team performance: Perceptions of American and Russian managers, International Journal of Cross Cultural Management, 4(2): 253-270.

Mumby,D. (2005) Theorizing resistance in organization studies. Management Communication Quarterly, 19: 19-44.

Mumby,D. (ed) (2011) Reframing difference in organizational communication studies: Research, pedagogy, practice. London: Sage.

Pollert,A. (1981) Girls, wives, factory lives. London: Macmillan.

Prasad,P. \& Prasad,A. (2000) Stretching the iron cage: The constitution and implications of routine workplace resistance. Organization Science, 11(4): 387-403.

Prasad,P. (2005) Crafting qualitative research: Working in the post-positivist traditions. Armonk, N.Y.: M.E. Sharpe.

Putnam,L.L., Jahn,J. \& Baker,J.S. (2011) Intersecting difference: A dialectical perspective. In Mumby,D. (ed), Reframing difference in organizational communication studies: Research, pedagogy, practice. London: Sage, pp. 31-53.

Reynolds,M. \& Trehan,K. (2003) Learning from difference? Management Learning, 34: 163-180.

Sewell,G. (1998) The discipline of teams: The control of team-based industrial work through electronic and peer surveillance. Administrative Science Quarterly, 38: 397-428.

Sewell,G. (2001) What goes around comes around: Inventing a mythology of teamwork and empowerment. Journal of Applied Behavioural Science, 37(1): 70-89.

Sinclair,A. (1992) The tyranny of a team ideology. Organization Studies, 13(4): 611-626.

Strauss,A. \& Corbin,J. (1998) Basics of qualitative research: Techniques and procedures for developing grounded theory. Thousand Oaks, CA: Sage.

Taylor,P. \& Bain,P. (2003) 'Subterranean worksick blues': Humour as subversion in two call centres. Organization Studies, 24(9): 1487-1509. 
1

2

3

4

5

6

7

8

9

10

Thomas,R. \& Davies,A. (2005a). Theorizing the micro-politics of resistance: New public management and managerial identities in the UK public services. Organization Studies, 26(5): 683-706.

Thomas,R. \& Davies,A. (2005b). What have the feminists done for us? Feminist theory and organizational resistance. Organization, 12(5): 711-740.

Thomas,R. \& Hardy,C. (2011) Reframing resistance to organizational change, Scandinavian Journal of Management, 27(3): 322-331.

Thompson,L. (2011) Making the team, $4^{\text {th }}$ ed. Upper Saddle River NJ: Prentice Hall.

Tourish,D. (2013) The dark side of transformational leadership. London: Routledge.

Townsend,K. (2005) Electronic surveillance and cohesive teams: Room for resistance in an Australian call centre? New Technology, Work and Employment, 20(1): 47-59.

Westwood,S. (1984) All day, every day: Factory, family, women's lives. London: Pluto.

Willis,P. (1977) Learning to labour. Aldershot, UK: Saxon House.

Zanoni,P. \& Janssens,M. (2007) Minority employees engaging with (diversity) management: An analysis of control, agency and micro-emancipation. Journal of Management Studies, 44: 13711397. 
Table 1: Team membership; number out of 7 original members (28 total)

(Note - 1 member from each team involuntarily left the company during or shortly following the programme; interviews were conducted with the remaining 24 members.)

\begin{tabular}{|l|c|c|c|c|c|}
\hline $\begin{array}{l}\text { Member characteristics/ } \\
\text { dimensions }\end{array}$ & Team 1 & Team 2 & Team 3 & Team 4 & $\begin{array}{l}\text { Total on each } \\
\text { dimension }\end{array}$ \\
\hline Director-level employees & 2 & 3 & 2 & 2 & 9 \\
Nationalities & 5 & 5 & 6 & 6 & 22 \\
$\begin{array}{l}\text { Regular work locations } \\
\text { (international) }\end{array}$ & 4 & 4 & 5 & 6 & 19 \\
Women & 2 & 2 & 2 & 2 & 8 \\
\hline
\end{tabular}

Table 2: Nationality, title, sex and current work location, by project group, of remaining 24 participants

\begin{tabular}{l|l|l} 
Project Teams & MEMBERS' NATIONALITY, TITLE \& & $\begin{array}{l}\text { MEMBERS' CURRENT } \\
\text { WORK LOCATION }\end{array}$ \\
\hline SEX
\end{tabular}

Team 1

Team 2

Team 3

Team 4
Mexican, Regional Manager, M

Canadian, Director, $\mathrm{M}$

British/West Indies, Manager, F

Canadian, Assistant Director, M

British, Director, $\mathrm{M}$

Slovakian, Assistant Manager, F

South African, Comptroller, F

French, Manager, F

French, Director, M

Canadian, Director, $\mathrm{M}$

British/Hong Kong, Senior Counsel, M

Chinese, Manager, $\mathrm{M}$

Swedish, Regional Manager, F

Pakistani, Director, M

Malaysian, Regional Director, M

Swiss, Assistant Manager, M

Canadian, Director, $M$

Paraguayan, Financial Analyst, F

Lebanese, Country Manager, M

French, Manager, F

British, Assistant Manager, M

French/Spanish, Manager, M

British, Director, M

Sri Lankan, Assistant Director, M
Costa Rica

Canada

Canada

Canada

France

Czech Republic

South Africa

Canada

Switzerland

Canada

Canada

China

Switzerland

Switzerland

Singapore

Switzerland

Canada

Panama

Lebanon

Canada

Switzerland

Spain

Switzerland

Singapore 
Table 3: Data collection methods

'This team member's nationality (i.e. from the former Easter Bloc countries) may have reinforced perceptions of her as being different or 'other'.

ii GRIP stands for 'Goals, Roles, Interpersonal Relations, Performance.'

iii One reviewer suggested that a closer focus on masculinity may be a useful way of theorizing these dynamics. However, our findings pointed to the primary importance of other aspects of (international) difference as informing resistance in this study. We recognize the importance of masculinity/ies and gender more broadly for understanding workplace resistance and control.

${ }^{\text {iv }}$ Focusing on gender and diversity, Putnam, Jahn and Baker (2011) identify three meanings of difference found in the organizational literature, namely as: deficient, added value, and discursive practices. They propose a fourth way of exploring intersecting difference, that of managing dialectical tensions. Future work may usefully apply Putnam et.al.'s emphasis on exploring intersecting difference through dialectical perspectives, to the difference-resistance relationship. 